\title{
Cerasomes: A New Family of Artificial Cell Membranes with Ceramic Surface
}

\author{
Jun-ichi Kikuchi and Kazuma Yasuhara \\ Nara Institute of Science and Technology (NAIST) \\ etpan
}

\section{Introduction}

Organic-inorganic hybrid materials have attracted much attention in the field of materials science because of their great potential for use in a wide variety of applications through fusion of individual organic and inorganic properties (Schmidt, 1994; Mackenzie, 1994; Sanchez et al., 2001; Schottner, 2001). Up to the present time, various kinds of material combinations and synthetic strategies have been developed. The sol-gel method is one of the most powerful techniques to prepare hybrid materials and has provided moderate preparative conditions for the construction of inorganic oxide frameworks that are derived from hybrid materials (Sakka, 2005). In particular, the preparation of novel materials with organized nanostructures is a fascinating research subject in the field of hybrid materials (Ulman, 1996; Ozin, 2000; Dabbs \& Aksay, 2000; Scott et al., 2001; van Bommel et al., 2003; Cölfen \& Mann, 2003). These approaches are generally based on sol-gel techniques that utilize the presence of molecular assemblies as templates, such as rod-like micelles (Yanagisawa et al., 1990; Kresge et al., 1992; Inagaki et al., 1999), block-copolymers (Krämer et al., 1998; Melosh et al., 1999; Ryoo et al., 2000), microemulsions (Sims et al., 1998; Feng et al., 2000), organogels (Ono et al., 1998), cast films of bilayer membranes (Sakata \& Kunitake, 1990) and bilayer vesicles (Hubert et al., 2000). Thus, the properties of nanohybrids depend on their nanostructures, especially the structure at the interface between the inorganic and organic components. Pre-organization by employing non-covalent interactions between an organic template and an inorganic precursor is known to be very important. However, the interface between the organic and inorganic components in these hybrids seems to be structurally ambiguous and more difficult to control at the molecular level than the individual component structures. Additionally, most of these materials are composed of inorganic components alone, and the organic portions are simply employed as templates.

In contrast, a novel class of layered organic-inorganic nanocomposites composed of amphiphilic molecules with a covalent bond between the silicate and the surfactant has been developed in recent years (Huo et al., 1996; Shimojima et al., 1997; Moreau et al., 2001; RuizHitzky et al., 2002; Zhang et al., 2004). These materials offer great potential because the hybrid precursors can form three-dimensional networks during the self-assembling process, whereby inorganic layers and organic moieties are covalently linked with stable Si-C bonds. We recently developed cerasomes, a novel type of organic-inorganic nanohybrid, through a combination of sol-gel reactions and self-assembling of lipidic organotrialkoxysilanes in aqueous media to form vesicles covered with silicate surfaces (Katagiri et al., 1999). A 
cerasome is composed of a spherical lipid-bilayer membrane having an internal aqueous compartment, like so-called liposomes formed with phospholipids or synthetic lipids (Torchilin \& Weissig, 2003; Kunitake, 1992), but is additionally covered with a silicate, surface framework (Fig. 1). While liposomes are widely used as biomembrane models and functional nanocapsules, their morphological instability is always a serious challenge for practical applications. It is hoped that cerasomes will overcome this limitation through the existence of a surface, silicate layer. Moreover, we can say that a cerasome is a novel organic-inorganic nanohybrid having a precisely designed nanostructure. That is, the thicknesses of both the organic and inorganic layers of a cerasome are attributed to the molecular structure of the cerasome-forming lipid, and the vesicular size of a cerasome is basically controllable by applying conventional methodologies for preparing monodispersed liposomes.

In this article, we review the design and preparation of cerasomes, as well as their morphological characterization. Additionally, the potential of the cerasome as a new family of artificial cell membranes is described from the viewpoints of surface modification versatility, hierarchical integration as a multicellular model and its functions as a cellfriendly drug carrier and molecular device.

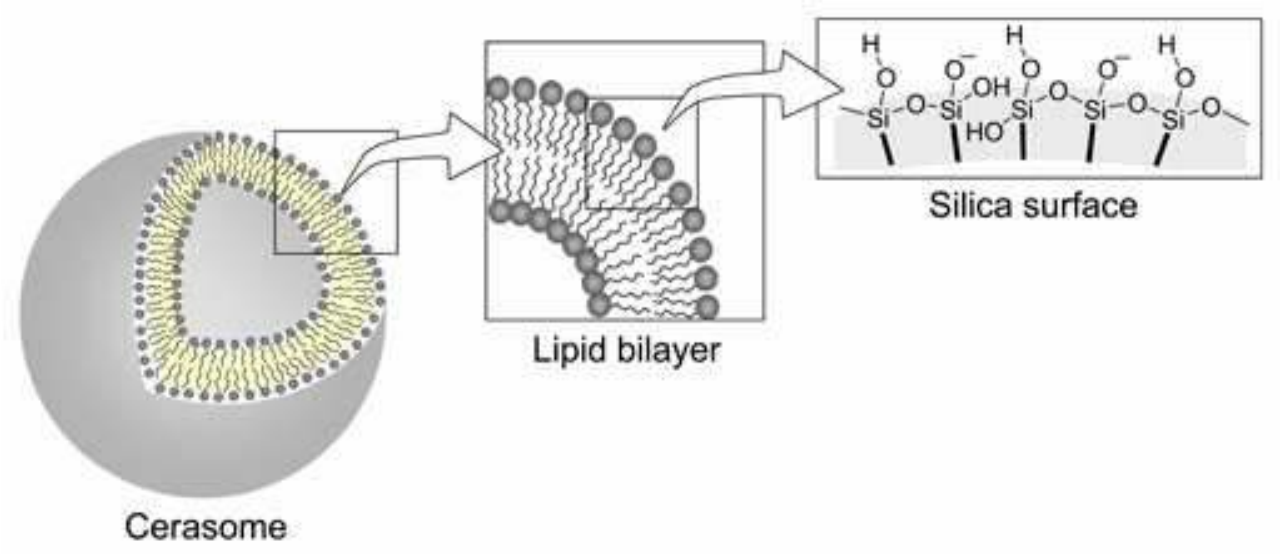

Fig. 1. Schematic drawing of a cerasome.

\section{Design and preparation of cerasomes}

The basic idea for designing a bilayer-forming lipid has been referred to as the concept of critical packing parameters for lipid assemblies (Israelachivili et al., 1976). Additionally, we considered the importance of a connector unit, which can form intermolecular hydrogen bonds to enhance morphological stability of the lipid assembly between the hydrophobic alkyl chains and the hydrophilic regions within a lipid molecule (Brockerhoff, 1977). We previously revealed the effect of a connector unit by systematic investigations of so-called peptide lipids, which have an amino acid or an oligopeptide moiety between the hydrophobic tail and the hydrophilic head (Murakami \& Kikuchi, 1991). Our design of the cerasome-forming lipids takes these points into account, as well as the simplicity of synthesis. In addition, the silanol group as a head moiety is protected by ethoxy groups to store the synthesized lipid stably. The general molecular structure of a cerasome-forming 
lipid is shown in Fig. 2. Upon hydrolysis of the triethoxysilyl group, the lipid is converted into an amphiphilic structure to form a lipid bilayer in aqueous media. Condensation among the silanol groups of the relatively hydrophobic membrane surface proceeds to develop a silica-like inorganic framework, or a siloxane network, resulting in a cerasome.

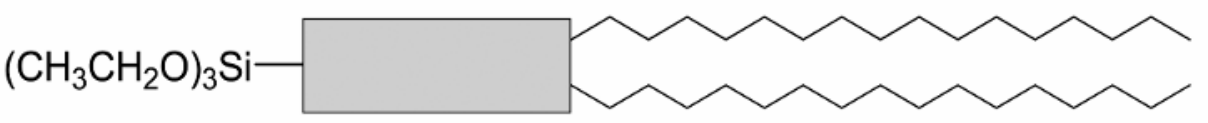

\section{Inorganic precursor Connector unit Hydrophobic tail}

Fig. 2. General molecular structure of a cerasome-forming lipid.

Cerasome-forming lipids prepared along this design concept are shown in Fig. 3. First, we synthesized a cerasome-forming lipid (1) by simple condensation reactions between the three molecular components: dihexadecyamine, succinic anhydride and 3aminopropyltriethoxylsilane (Katagiri et al., 1999). Cerasome-forming lipids with a simple molecular structure having one urea group (2) or one amide group (3) in the connector unit were also prepared (Hashizume et al., 2003). The cationic cerasome-forming lipids $(\mathbf{4}, \mathbf{5})$ with a similar molecular framework of the typical peptide lipid, composed of the hydrophobic double-chain segment, quaternary ammonium head and an amino acid residue interposed between them, were developed by replacing the methyl group of the trimethylammonium head to form a 3-triethoxysilylpropyl group (Katagiri et al., 2002a; Sasaki et al., 2006). A cerasome-forming lipid with two triethoxysilyl heads (6) was designed to tune the siloxane network on the cerasome surface (Hashizume et al., 2004). To provide biodegradability to the cerasome, a phospholipid with a triethoxysilyl head (7) was also designed and synthesized.

The preparation procedure for cerasomes with a multiwalled vesicular structure is basically analogous to that of the liposomes formed with phospholipids. In general, we can adopt two kinds of preparation methods. One is the direct dispersion of the cerasome-forming lipid in aqueous media by vortex-mixing (Katagiri et al., 2007). The procedure is very simple technically; however, we should pay attention to the reaction conditions, especially the effect of $\mathrm{pH}$ (Ariga et al., 2000; Katagiri et al., 2001). As for the water-insoluble lipids, such as lipids (1-3), hydrolysis of the triethoxysilyl head group of the proamphiphile gradually proceeds to give a corresponding amphiphilic molecule. This lipid readily forms a selfassembly of the liposome-like bilayer membrane in aqueous media. In addition, condensation among the silanol groups on the relatively hydrophobic membrane surface proceeds spontaneously to develop a siloxane network. However, if the hydrolysis and subsequent condensation is much faster prior to the self-assembly, formation of the bilayer structure may be disturbed. Therefore, control of the reaction rate in the sol-gel process, especially the hydrolysis, seems to be important to cerasome formation.

For example, lipid (1) does not change to the corresponding amphiphilic form after prolonged vortex-mixing in aqueous media under a neutral $\mathrm{pH}$ condition and remains as oil droplets, primarily because of the extremely slow hydrolysis of the head group. On the other hand, a translucent solution characteristic of a liposomal dispersion is obtained under moderate acidic conditions at $\mathrm{pH} 3$, where hydrolysis of the ethoxysilyl groups is gently preceded by mild acid catalysis. Under stronger acidic conditions at $\mathrm{pH} 1$, however, a stable 
<smiles>CCCCCCCCCCCCCCCCCCCCCCCCN(CCCCCCCCC)C(=O)CCC(=O)NCCC[SiH2]OCC</smiles><smiles>CCCCCCCCCCCCCCCCCCCCCCCCCCN(CCCCCCCC)C(=O)NCCC[SiH2]OCC</smiles><smiles>CCCCCCCCCCCCCCCCCCCCCCCCCCN(CCCCCCCC)C(=O)CCC[SiH2]OCC</smiles>

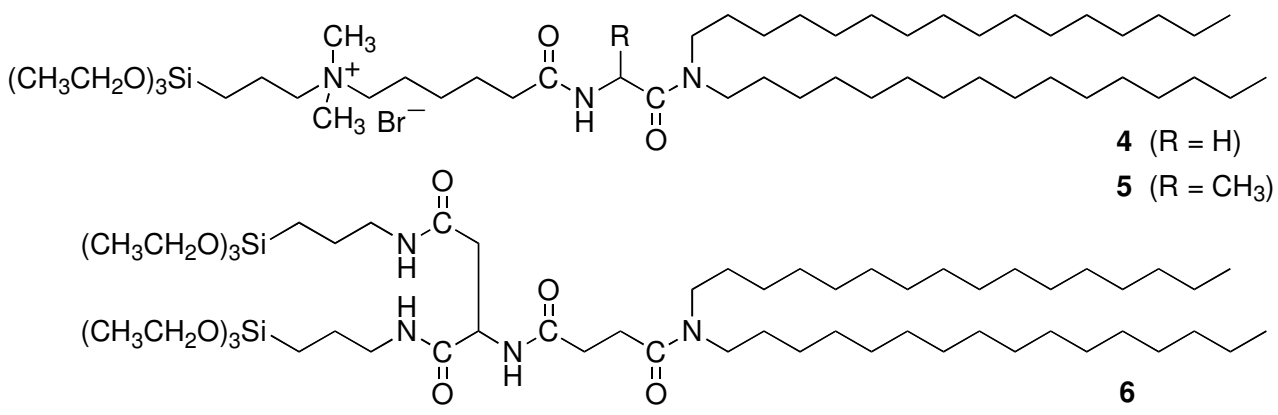<smiles>CCCCCCCCCCCCC(=O)OCC(COP(=O)(O)OCCNC(=O)NCCC[SiH2]OCC)OC(=O)CCCCCCCCC</smiles>

Fig. 3. Structural formulae of cerasome-forming lipids.

dispersion is not obtained, and precipitation is observed immediately. In this case, the hydrolysis and subsequent condensation reaction are so fast that the formation of the vesicular structure is prevented. At $\mathrm{pH} \mathrm{12,} \mathrm{the} \mathrm{resulting} \mathrm{solution} \mathrm{is} \mathrm{translucent,} \mathrm{but} \mathrm{oil}$ droplets remain. Thus, the hydrolysis seems to proceed heterogeneously under basic conditions. The behaviors observed under the different $\mathrm{pH}$ conditions can be explained on the basis of a generally accepted mechanism for hydrolysis of alkoxysilane compounds in the sol-gel process, as follows. Under acidic conditions, hydrolysis of the triethoxysilyl group continues equally for each of the proamphiphile molecules in a one-by-one manner. This process provides a suitable condition for the preparation of the lipid bilayer assembly. On the other hand, under basic conditions, particular molecules are preferentially hydrolyzed, while the other molecules remain as unreacted species. This process leads to heterogeneous hydrolysis, and various reaction stages of the lipid are observed. Thus, basic conditions seem to be unsuitable for the preparation of cerasomes. In practice, the hydrolysis behavior of cerasome-forming lipids can be monitored by ${ }^{1} \mathrm{H}$ NMR spectroscopy. 
Regarding the cerasome-forming lipids with good water solubility, such as lipids (4) and (5), the direct dispersion method was adopted for its ease and utility.

The second procedure of cerasome preparation is the ethanol sol injection method (Katagiri et al., 2003). In this method, the hydrolysis of cerasome-forming lipids is performed by incubating an acidic ethanol solution of the lipids for an appropriate time. The sol thus obtained is injected into water, and the solution is incubated for an additional $24 \mathrm{~h}$. This method is useful for cerasome-forming lipids with poor water solubility.

In general, the size of the multiwalled cerasomes is in the range of sub-micrometers. Upon sonication of the aqueous dispersion of the cerasome, the multiwalled vesicles convert into the corresponding single-walled vesicles with a diameter less than $100 \mathrm{~nm}$ (Katagiri et al., 2007; Sasaki et al., 2006). For sonication conditions, the use of a probe-type sonicator at $30 \mathrm{~W}$ power above the phase transition temperature of the lipids for $3 \mathrm{~min}$ is generally recommended. The vesicular size can be evaluated by dynamic light scattering (DLS) measurement. Cell-sized cerasomes with a diameter larger than $1 \mu \mathrm{m}$ can also be prepared by employing the preparation method of giant liposomes (Luisi \& Walde, 1999).

\section{Morphological characterization of cerasomes}

\subsection{Aggregate morphology}

The aggregate structures of cerasomes can be evaluated by means of various microscopic measurements, such as transmission electron microscopy (TEM), scanning electron microscopy (SEM), atomic force microscopy (AFM) and optical microscopy. For TEM measurements of cerasomes, we can use three kinds of imaging techniques (Kikuchi \& Yasuhara, in press). First, negative staining with heavy metal ions is a simple and convenient technique. For example, a negatively-stained TEM image of a cerasome formed with lipid (4), using the direct dispersion method, is shown in Fig. 4 (a). An internal view of
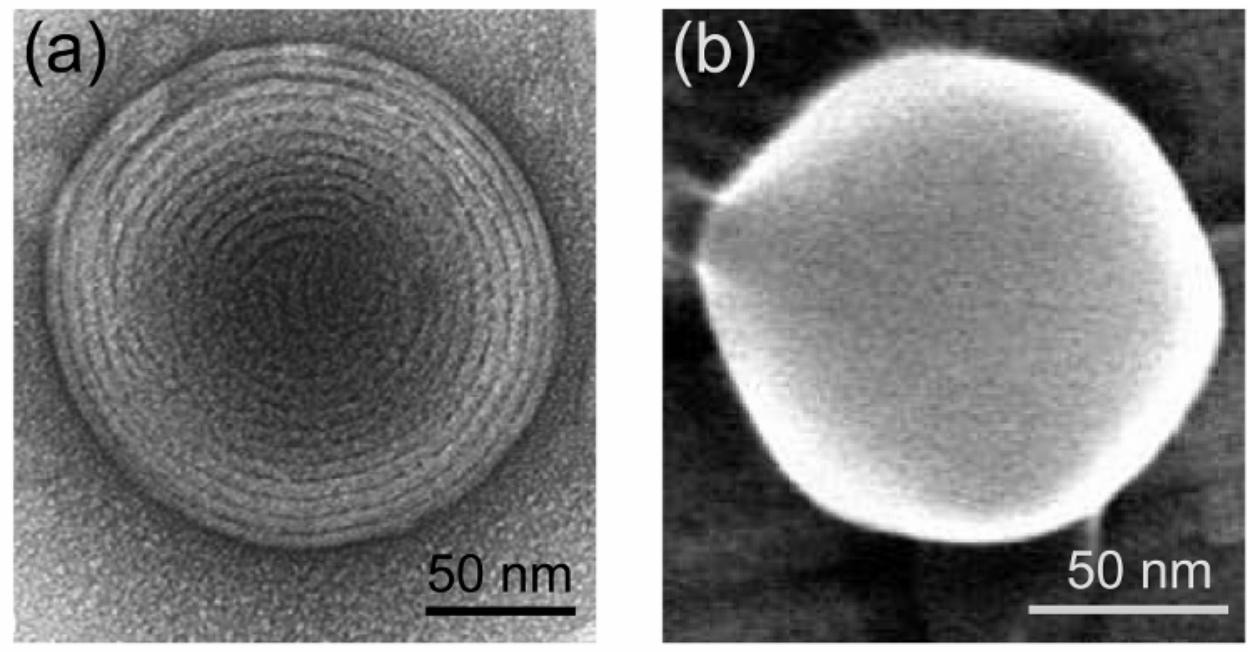

Fig. 4. Microscopic images of multiwalled cerasomes: a negatively stained TEM image of a cerasome formed with lipid (4) (a) and a SEM image of a cerasome formed with lipid (2) (b). 

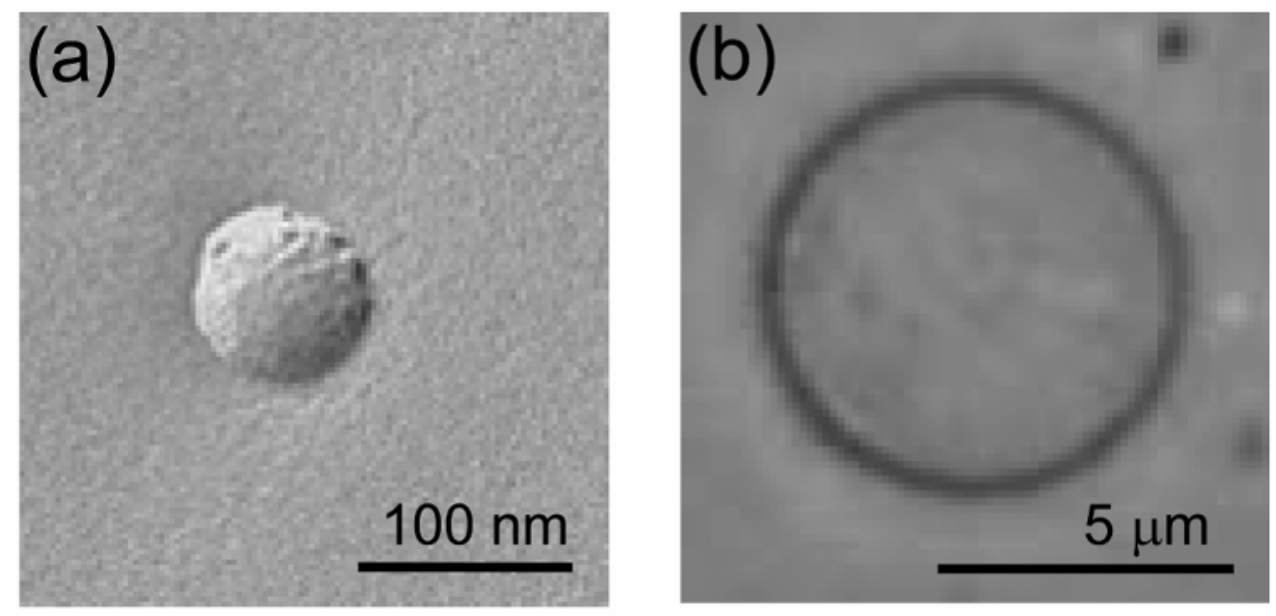

Fig. 5. Microscopic images of single-walled cerasomes: a freeze-fracture TEM image of a small cerasome formed with lipid (5) (a) and a phase contrast image of a giant cerasome formed with lipid (5) (b).

the multiwalled vesicles with a bilayer thickness of about $5 \mathrm{~nm}$ was clearly confirmed. A similar image was obtained by cryogenic TEM without a staining agent. On the other hand, freeze-fracture TEM imaging can provide information on the vesicular surface structure. Figure 5 (a) shows a surface image of a single-walled cerasome formed with lipid (5), as observed by freeze-fracture TEM.

In general, SEM is a challenging technique for imaging conventional liposomes formed with phospholipids because of the poor structural integrity of the samples. However, cerasomes can be visualized by SEM because of their high morphological stability. An SEM image of a multiwalled cerasome formed with lipid (2), using the ethanol sol injection method, is shown in Fig. 4 (b). The enhanced morphological stability of the cerasome also allows clear AFM imaging, as described later. For micrometer-sized giant cerasomes, optical microscopy is a powerful tool to provide dynamic imaging. Figure $5(\mathrm{~b})$ shows a phase contrast image of a giant cerasome formed with lipid (5). By using an appropriate fluorescent probe, we can visualize the lipid layer of a cerasome and its inner aqueous phase, separately.

\subsection{Surface siloxane network}

One of the important characteristics of the cerasomes is the presence of a surface siloxane network. This inorganic framework provides the cerasome much higher morphological stability compared with that of a conventional liposome.

The formation of siloxane bonds on the surface of a cerasome formed with lipid (1) was evaluated by Fourier transform infrared spectroscopy (Katagiri et al., 2007). Stretching bands assigned to the Si-O-Si and Si-OH groups were observed around 1100 and $950 \mathrm{~cm}^{-1}$, respectively. The former peak intensity was much weaker than the latter in the cerasome in the aqueous dispersion state. Thus, it is suggested that the cerasome had a silica-like surface with a siloxane framework, but the degree of polymerization was not particularly high. The detectable species of lipid oligomers in the cerasome as evaluated by matrix assisted laser 
desorption ionization time-of-flight mass spectrometry (MALDI-TOF-MS) spectra are listed in Table 1. Trimethylsilylation was performed for the aqueous dispersion samples of a cerasome prepared after $10 \mathrm{~h}$. While the monomer, dimer and trimer species were also detected in the sample as prepared, oligomers with higher molecular weights such as tetramers and pentamers were also detected in the sample during the prolonged incubation. This implies that the siloxane network grew as the incubation time increased. From cryoscopic measurements, the number-average molecular weight was determined to be 1300 for the aqueous dispersion of the cerasome incubated for $10 \mathrm{~h}$. This value corresponds to the molecular weight of the dimer species. On the other hand, the size of the cerasome did not change appreciably after the allotted incubation time, as confirmed by TEM and DLS measurements. Accordingly, the siloxane network was not so highly developed on the cerasome surface. These observations were also supported by a computer-aided molecular model study, since the length of the Si-O-Si bond was much shorter than the calculated diameter of the cross-section of the dialkyl tail.

\begin{tabular}{lcc}
\hline \multirow{2}{*}{ Species } & \multicolumn{2}{c}{ Molecular weight } \\
\cline { 2 - 3 } & Observed a $^{\text {C }}$ & Calcd \\
\hline Monomer & 901.7 & 900.7 \\
Dimer & 1640.4 & 1641.0 \\
Trimer (cyclic) & ud & 2217.9 \\
Trimer (linear) & 2380.3 & 2380.3 \\
Tetramer (cyclic or branched) & 2957.3 & 2957.3 \\
Tetramer (linear) & 3117.4 & 3119.6 \\
Pentamer (cyclic or branched) & 3695.3 & 3696.7 \\
Pentamer (linear) & ud & 3859.0 \\
\hline
\end{tabular}

a Evaluated by MALDI-TOF-MS spectra after incubation for $10 \mathrm{~h}$. ud: undetectable.

Table 1. Detectable species of lipid oligomers for a cerasome formed with lipid (1)

Surfactant solubilization is a useful method to evaluate morphological stability of liposomes in aqueous media. Thus, the resistance of a cerasome formed with lipid (1) against a nonionic surfactant, Triton X-100 (TX-100), was evaluated from the light scattering intensity of the vesicles (Katagiri et al., 2007). A liposomal membrane formed with 1,2-dimyristoyl-snglycero-3-phosphocholine (DMPC) was used as a reference. When three equivalents of TX100 were added to the DMPC liposome, the light scattering intensity was drastically decreased, indicating a collapse of the vesicles. In contrast to the DMPC liposome, the cerasome exhibited a remarkable morphological resistance toward TX-100, and the light scattering intensity of the cerasome incubated for $24 \mathrm{~h}$ did not change, even in the presence of 36 equivalents of TX-100. Such surprising morphological stability of the cerasome was also confirmed by the DLS measurements. Morphological stability of such a cerasome seems to be superior to that of an excellent example of the polymerized liposomes recently developed (Mueller \& O'Brien, 2002). It is noteworthy that the resistance of the cerasome toward TX-100 was insufficient immediately after preparation. Thus, it is clear that the morphological stability of the cerasome comes from development of the siloxane network 
on the vesicular surface. As for the cationic cerasomes prepared from lipids (4) or (5), the resistance against TX-100 was comparable to that of a conventional liposome, even after prolonged incubation. However, cationic cerasomes have an extremely high morphological stability against other kinds of surfactants, such as cetyltrimethylammonium bromide (CTAB), which completely dissolves DMPC liposomes (Sasaki et al., 2004). Accordingly, we can control the morphological stability of the vesicles through modification of the molecular design of the cerasome-forming lipids.

\subsection{Phase transition and phase separation behavior}

Phase transition parameters for the cerasomes were evaluated by differential scanning calorimetry (DSC). The enthalpy change from the gel to liquid-crystalline state $(\Delta H)$ and the temperature at the peak maximum $\left(T_{\mathrm{m}}\right)$ for the aqueous dispersion of a cerasome prepared from lipid (1) were $47.5 \mathrm{~kJ} \mathrm{~mol}^{-1}$ and $10.5^{\circ} \mathrm{C}$, respectively. Upon sonication of the cerasome with a probe-type sonicator for $10 \mathrm{~min}$ at $30 \mathrm{~W}$, the $\Delta H$ value decreased to $11.5 \mathrm{~kJ} \mathrm{~mol}^{-1}$, whereas the $T_{\mathrm{m}}$ value did not change. For a cerasome formed with lipid (4) in the aqueous dispersion state, the $\Delta H$ and $T_{\mathrm{m}}$ values were $33.3 \mathrm{~kJ} \mathrm{~mol}^{-1}$ and $25.7^{\circ} \mathrm{C}$, respectively. These phase transition parameters are comparable to those for peptide lipids previously reported (Murakami \& Kikuchi, 1991). Upon sonication of the cerasome prepared from lipid (4) with a probe-type sonicator for $10 \mathrm{~min}$ at $30 \mathrm{~W}$, the endothermic peak for the phase transition apparently disappeared. We have previously clarified that the transformation of the multiwalled vesicle to the corresponding single-walled vesicle is reflected in the decrease of both the $\Delta H$ and $T_{\mathrm{m}}$ values (Murakami \& Kikuchi, 1991). Additionally, $\Delta H$ is more sensitive than $T_{\mathrm{m}}$ to such morphological changes. Since it is well known that the multiwalled vesicles formed with conventional liposomes generally transform to single-walled vesicles under the sonication conditions employed in this study, cerasome (1) is more tolerant towards morphological changes than the liposome-forming lipids. Formation of the siloxane network on the vesicular surface can prevent such morphological transformations.

Cerasomes enhance the creation of lipid domains in the vesicle (Hashizume et al., 2006a). For example, a cerasome prepared from the mixture of lipid (1) and 1,2-dipalmitoyl-snglycero-3-phosphatidylcholine (DPPC) formed a phase-separated lipid domain, as evaluated by DSC. That is, the aqueous dispersion of the homogeneous mixture of these lipids showed two phase transition peaks originating from the individual lipids. Similar phase separation behavior was observed in the cerasome formed with lipid (1), and the peptide lipid replaced the triethoxysilylpropyl group of lipid (5) as a methyl group. Such marked phase separation was not detected for the bilayer vesicle formed with DPPC and the peptide lipid. These results are mainly attributable to the polymerizable nature of the cerasome-forming lipid.

\section{Surface modification of cerasomes}

As mentioned, the surface of a cerasome is covered with a number of small siloxane oligomers. Since a cerasome exhibits analogous reactivity to the inorganic silica surface, we can modify a cerasome surface to give various unique organic-inorganic hybrid vesicles (Fig. 6).

\subsection{Tuning of the siloxane network}

Development of the siloxane network on a cerasome surface can be tuned when the cerasome is prepared by the ethanol sol injection method in the presence of 


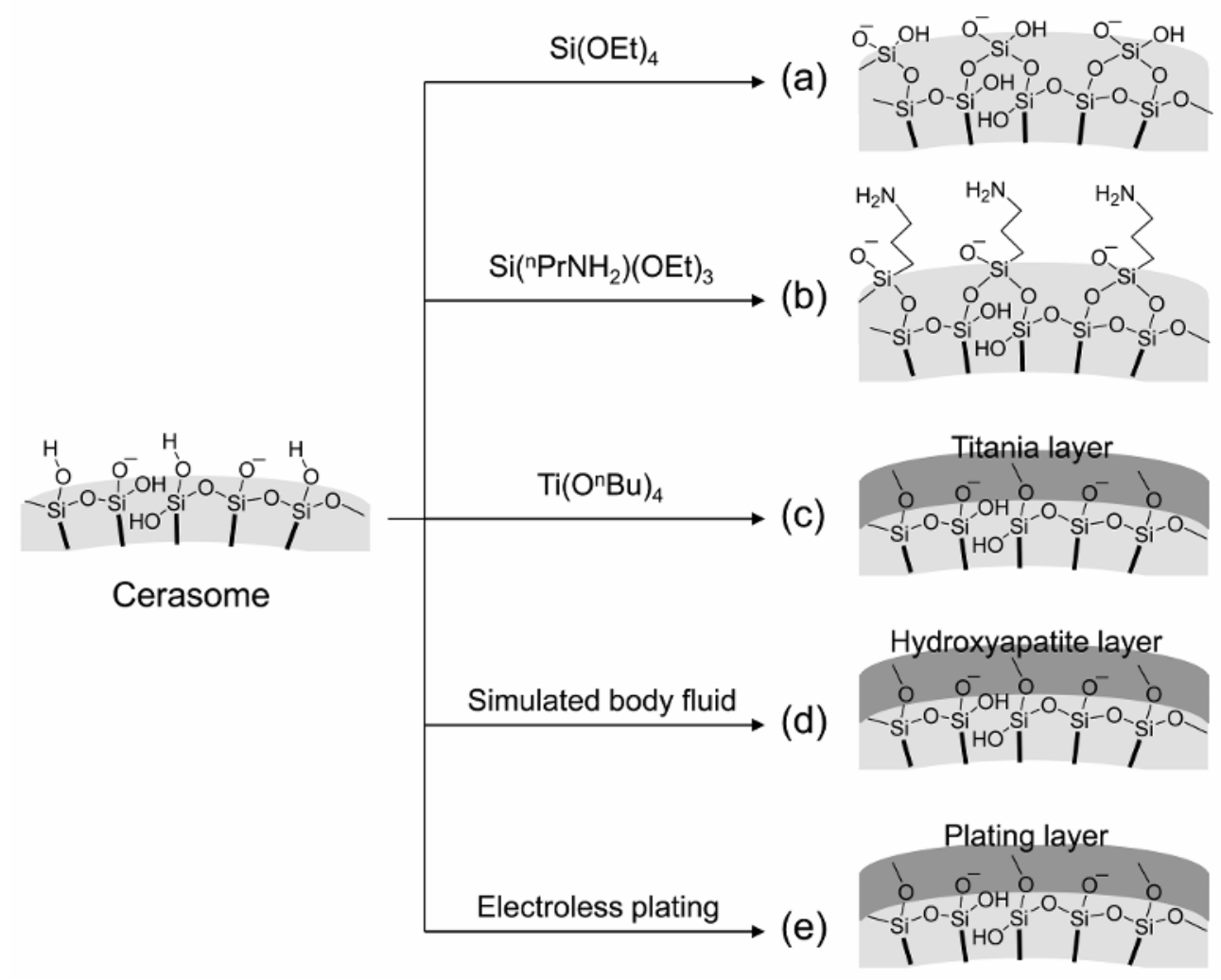

Fig. 6. Modification of the cerasome surface: development of a siloxane network (a), introduction of an organic functional group (b), coating with titania (c), hydroxyapatite (d) and a metallic nanolayer (e).

tetraethoxysilane (TEOS) (Katagiri et al., 2003). As such, when the sol prepared from lipid (1) with TEOS after $12 \mathrm{~h}$ incubation was injected into an aqueous solution under various $\mathrm{pH}$ conditions, the monodispersed and stable aggregates of the cerasome were formed. The hydrodynamic diameter and polydispersity index evaluated from the DLS measurements were $250-270 \mathrm{~nm}$ and $0.05-0.13$, respectively. Formation of the cerasomes with a diameter of 150-300 nm was observed for all the samples with and without a surface modification by TEOS, as confirmed by TEM. The values were in well agreement with those obtained from the DLS measurements.

Differences in the development of the siloxane network can be evaluated from a $\mathrm{pH}$ dependence of the zeta-potential of the cerasomes. For the cerasome without a surface modification, the zeta-potentials were in a range of +10 to $-70 \mathrm{mV}$. The isoelectric point of the cerasome appeared at 4.3. Thus, the present cerasome possessed large negative charges under neutral and basic conditions, reflecting deprotonation of the silanol groups on the cerasome surface. For the cerasome modified with TEOS, a lower shift of the isoelectric point to 3.2 was observed. It has been reported that the isoelectric point of the typical silica particles derived from the sol-gel method lies in the range of 2-3, and the zeta-potentials for 
the particles are ranged from +20 to $-80 \mathrm{mV}$ in the analogous $\mathrm{pH}$ region (Nishimori et al., 1996). These results indicate that the surface electrical state of the cerasome modified with TEOS resembled that of the silica particles rather than that of the cerasome without surface modification. Thus, lipid (1) and TEOS were effectively co-polymerized to form the cerasome with a well-developed siloxane network.

\subsection{Coating with functional layers}

Surface modification of a cerasome with functional amino groups is readily achieved in a similar manner by replacing TEOS with 3-aminopropyltriethoxysilane (APS) (Katagiri et al., 2003). For a cerasome formed with lipid (1) in the presence of APS, the hydrodynamic diameter and polydispersity index were $210-220 \mathrm{~nm}$ and $0.19-0.25$, respectively. The isoelectric point evaluated from the $\mathrm{pH}$ dependence of the zeta-potential was shifted to 10.0 for the APS-modified cerasome. In the $\mathrm{pH}$ range lower than 10, the zeta-potential of the cerasome increased with a decrease of $\mathrm{pH}$ to reach $+100 \mathrm{mV}$ at $\mathrm{pH}$. The value is considerably higher than the corresponding maximal value of the cerasome derived from lipid (1) alone. Such a difference is attributable to an effective introduction of the amino group of APS on the former cerasome surface. Thus, in the physiological $\mathrm{pH}$ region, the cerasome prepared from lipid (1) without modification was present as a polyanionic vesicular particle, whereas the cerasome modified with APS was polycationic. Additionally, it may be possible to control the isoelectric point of the cerasome to a desired value by changing the molar ratio of lipid (1) and APS. Accordingly, we can prepare functionalized cerasomes modified with various alkoxysilane compounds by adopting this technique.

Using the ethanol sol injection method for cerasome preparation in the presence of titanium alkoxide, we can create a titania-coated cerasome (Hashizume et al., 2006b). Specifically, the cerasome-forming lipid $(\mathbf{1})$ and titanium tetrabutoxide, $\mathrm{Ti}(\mathrm{OnBu})_{4}$, were incubated in acidic aqueous ethanol in the presence of acetylacetone as a co-catalyst. The sol was injected into the aqueous media and followed photo-irradiation to produce a cerasome with a diameter of c.a. $150 \mathrm{~nm}$. The zeta-potential of the titania-coated cerasome changed from +30 to -40 $\mathrm{mV}$, depending on the medium $\mathrm{pH}$, and the isoelectric point was 4.8, which is comparable to that of colloidal titania, ranging between 5-7. The photocatalytic activity of the titaniacoated cerasome was confirmed by photolysis of methylene blue in aqueous media by means of electronic absorption spectroscopy.

Biomimetic mineralization of supramolecular scaffolds consisting of biomolecules or their analogues has received much attention with regard to the creation of novel biomaterials. Likewise, we applied biomimetic deposition of hydroxyapatite (HAp) onto cerasomes (Hashizume et al., 2010). When a cerasome formed with lipid (1) was immersed into a solution having 1.5 times higher ion concentration than that of simulated body fluid (SBF), the cerasome induced heterogeneous nucleation of HAp, as evaluated by means of SEM, energy-dispersive X-ray spectroscopy and X-ray diffraction. The HAp deposition was further accelerated when dicarboxylic and monocarboxylic acid groups were displayed on the cerasome surface. These carboxylic acid groups were expected to enhance calcium ion binding to the cerasome surface, causing an increase of HAp nucleation sites. At lower surface concentrations on the cerasome surface, the dicarboxylic acid group is apparently more effective for HAp deposition than the monocarboxylic acid group. The HAp-coated cerasome is useful as a biocompatible material having unique properties deriving from the lipid bilayer structure of the cerasome. 
The other system that highlights advantages of cerasomes is an asymmetric bilayer coating of monodispersed colloidal silica particles (Katagiri et al., 2004a). The particles were first coated with a cerasome-forming lipid and then coated with a bilayer-forming lipid to form an asymmetric lipid bilayer structure, which is usually seen in biological systems, but difficult to reconstitute by conventional techniques.

\subsection{Coating with metallic nanolayers}

Novel liposomal membranes having a metallic surface, so called metallosomes, are prepared by electroless plating of cerasomes (Gu et al., 2008). The electroless plating of a cerasome formed with lipid (5) was performed by first binding palladium tetrachloride ions $\left(\mathrm{PdCl}_{4}{ }^{2-}\right)$ onto the cationic membrane surface through electrostatic interactions, then subsequently reducing this precursor catalyst to $\operatorname{Pd}(0)$ and finally depositing a layer of metal onto the cerasome surface using an appropriate plating bath. While the metallosome coated with an ultrathin Ni layer was successfully prepared by electroless Ni plating of the cerasome, it was not possible to derive the Ni-coated vesicle formed with the corresponding peptide lipid under similar plating conditions. Such results reflect the difference in the morphological stability of these vesicles. The characterization of the Ni-metallosomes was performed using various physical measurements, such as SEM, TEM, energy-dispersive X-ray spectroscopy, electron energy-loss spectroscopy and TEM tomography. The Ni layer thickness was controllable on the nanometer scale by changing the plating time. The gel to liquidcrystalline phase transition behavior of the Ni-metallosomes was observed by DSC, indicating that the metallosomes maintained the nature of the lipid bilayer membrane. Nimetallosomes with various sizes were prepared from the corresponding cerasomes in a diameter range of 50-5000 $\mathrm{nm}$. Metallosomes with an Au layer were also successfully obtained by electroless $\mathrm{Ni} / \mathrm{Au}$ substitution plating of Ni-metallosomes.
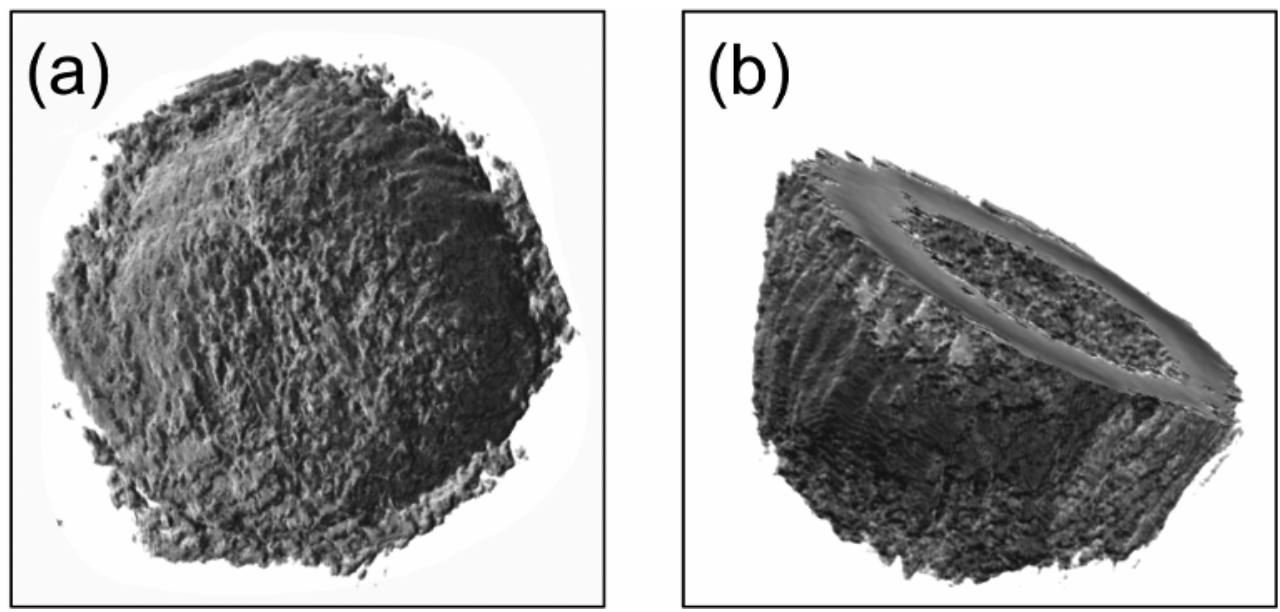

Fig. 7. Three-dimensional reconstitution of TEM images of a magnetic cerasome formed with lipid (2): the whole image (a) and the sliced image (b). 
A magnetic cerasome, an artificial cell membrane having ultrathin magnetic metallic layers on the surface, was prepared through electroless plating of a magnetic metal alloy onto a cerasome (Minamida et al., 2008). Figure 7 shows three-dimensional images of a magnetic cerasome derived from lipid (2), as observed by TEM tomography. High morphological stability in the cerasome was important for constructing the magnetic lipid vesicle, and insertion of an alkylated metal ligand into the cerasome was essential for the magnetic metal alloy deposition on the cerasome surface. The magnetic property was evaluated by means of vibrating sample magnetometry. The magnetic field-magnetism hysteresis loop for the magnetic cerasome at different temperatures revealed that the magnetic cerasomes exhibited ferromagnetism, reflecting the nature of the plated magnetic metal alloy. Additionally, fluorescence microscopic observations revealed that the magnetic cerasomes were collected reversibly on the slide glass surface and manipulated by an external magnetic field.

\section{Hierarchical integration of cerasomes}

\subsection{Three-dimensional integration on a substrate}

Lipid bilayer vesicles with an inner aqueous compartment have been extensively employed as biomembrane models. Thus, it would be important to develop a new methodology to form hierarchically integrated vesicular assemblies, since the multicellular bodies in biological systems can create highly organized architectures and exhibit more functions than unicellular bodies can. Three-dimensional integration of the cerasomes on a substrate is successfully achieved by employing a layer-by-layer assembling method. As such, an anionic cerasome formed with lipid (1) was assembled on a substrate covered with oppositely charged polycations (Katagiri et al., 2002b). AFM images of the anionic cerasome layer and the cationic polymer layer are shown in Fig. 8 (a). The integration process was monitored by measuring the absorption mass changes on a quartz crystal microbalance. A similar three-dimensional assembly was created with an APS-modified cationic cerasome derived from lipid (1) and an anionic polymer on a substrate (Katagiri et al., 2004b). The alternate layer-by-layer assembly of two types of vesicles was obtained by employing the combination of an anionic cerasome formed with lipid (1) and a cationic cerasome formed with lipid (4) as shown in Fig. 8 (b) (Katagiri et al., 2002a). Notably, three-dimensional integration of lipid vesicles on a substrate can be achieved by use of morphologically stable cerasomes, but not by conventional bilayer-forming lipids.

\subsection{Integration on DNA templates}

In general, the interactions of ionic lipid vesicles with oppositely charged polymers induce morphological changes of the vesicles. However, the vesicular structure of cerasomes is much more stable than that of conventional liposomes. Thus, we can expect to create multicellular models by employing multipoint electrostatic interactions of the cerasomes with ionic polymers in aqueous media. In fact, we observed that cationic cerasomes formed with lipid (5) assembled on the DNA templates, as shown in Fig. 9 (Matsui et al., 2007; Hashizume et al., 2008). Under similar conditions, cationic peptide lipid in which the triethoxysilylpropyl group of lipid (5) was replaced by a methyl group, could not maintain the vesicular shape to support fusion of the vesicles. 
(a)

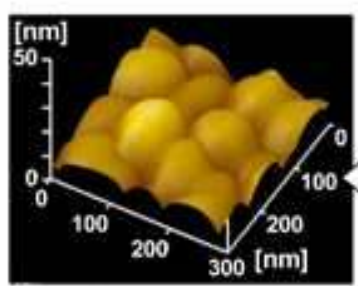

Anionic cerasome layer

(b)

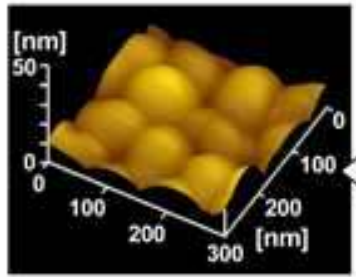

Anionic cerasome layer

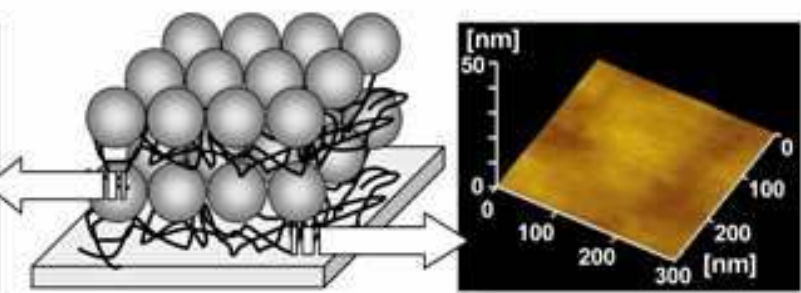

Cationic polymer layer
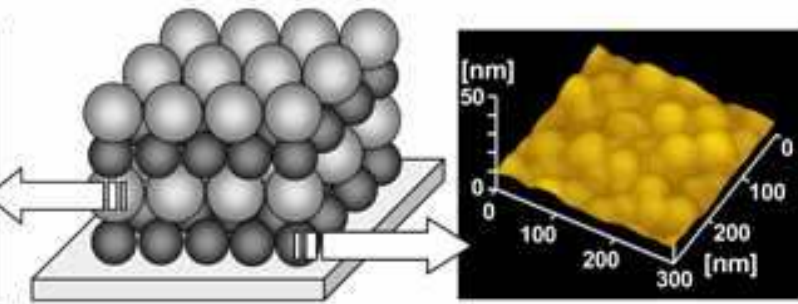

Cationic cerasome layer

Fig. 8. AFM images of three-dimensional self-assemblies of cerasomes on a mica substrate: layer-by-layer assembly of an anionic cerasome (1) with a cationic polymer (a) and a cationic cerasome (4) (b).
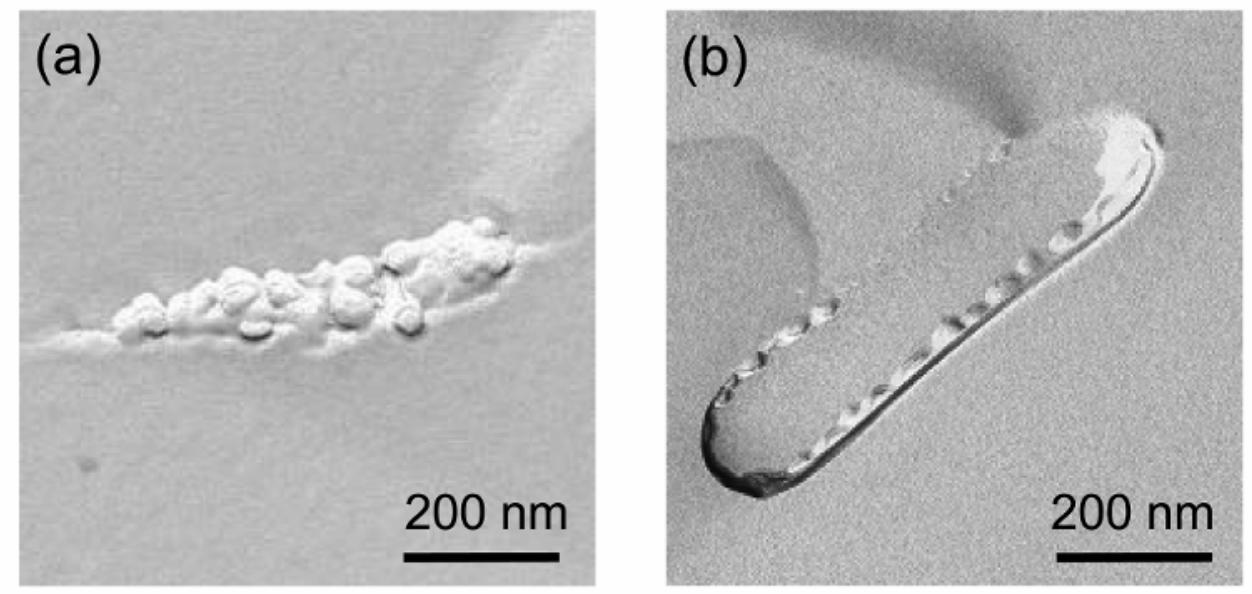

Fig. 9. Freeze-fracture TEM images of the self-assemblies of cationic cerasomes on DNA templates: assemblies of a cationic cerasome (5) on double-stranded DNA (a) and plasmid DNA (b). 


\section{Functionalization of Cerasomes}

\subsection{Potent drug carriers}

Since the discovery of lipofection (Felgner et al., 1987), cationic lipids have been widely used as transfection agents in gene delivery (Behr, 1993; Kabanov \& Kabanov, 1995; Mintzer \& Simanek, 2009). They form cationic liposomes, to which anionic DNAs are electrostatically bound, to form complexes (or lipoplexes) that are taken in the cells via endocytosis. This is, however, an oversimplified picture. Liposomes are by no means rigid or robust. They are potentially fusible with cell membranes and therefore, toxic. They also easily undergo DNAinduced fusion to give larger particles that have lower endocytosis susceptibility and poorer vascular mobility. Additionally, serum components can interfere with fragile liposomeDNA complexes. Size instability, cytotoxicity and serum incompatibility, which are actually interrelated, are thus major problems in the current lipofection technology.

Recently, we developed an excellent transfection system using a cationic cerasome as a gene carrier (Matsui et al., 2006; Sasaki et al., 2006). We found that the cerasome formed with lipid (5) was infusible. The monomeric cerasome complex of plasmid DNA in a viral size $(\sim 70$ $\mathrm{nm})$ indeed exhibited a remarkable transfection performance, such as high activity, minimized toxicity and serum-compatibility, toward uterine HeLa and hepatic HepG2 cells (Fig. 10). This was in marked contrast to the non-silylated reference lipid, which forms fused, huge particles with significantly lower activity, by a factor of $10^{2}-10^{3}$ and exhibited more pronounced toxicity. A couple of potential generalities of the present cerasome strategies with respect to nucleic acids to be delivered and cationic lipids as carriers are worth mentioning. The cerasome-plasmid complexation is strong and efficient, even at a stoichiometric lipid/nucleotide ratio. In this context, the cerasome could also be used as a size-regulated carrier for diverse types of functional nucleic acids, such as aptamers and siRNAs (Matsui et al., 2007). On the other hand, cerasomes encapsulating [70]fullerene also act as good carriers, exhibiting efficient photodynamic activity in HeLa cells (Ikeda et al., 2009).

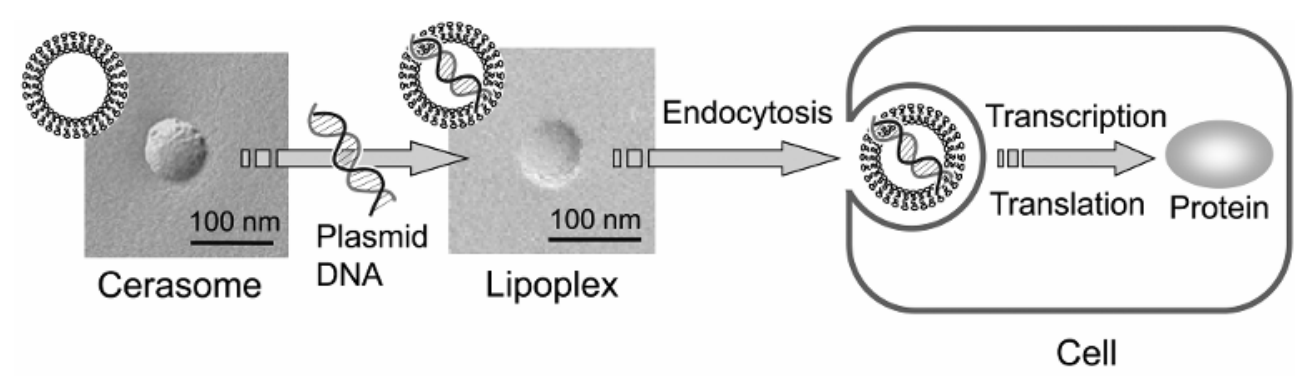

Fig. 10. Schematic representation of the transfection of a lipoplex formed with a cationic cerasome (5) and a plasmid DNA: images of the cerasome and its lipoplex were taken by freeze-fracture TEM.

\subsection{Molecular devices for information processing}

Signal transduction using molecules as information carriers is ingeniously designed in biological systems. Receptors and enzymes play leading roles for such information 
processing; however, biomembranes are also essential to provide a platform for the performance of these functional biomolecules. On these grounds, we have developed a biomimetic signal transduction system as a molecular device on artificial cell membranes (Kikuchi et al., 1999; Tian et al., 2005). When a molecular communication system was constructed on a cerasome formed with lipid (4), its signal transduction efficiency was much more effective than that created on the corresponding peptide lipid vesicle (Sasaki et al., 2004). The system contained a synthetic steroidal receptor and NADH-dependent lactate dehydrogenase, both embedded in the membrane through noncovalent interactions, as schematically shown in Fig. 11. A biologically important molecule, pyridoxal 5'-phosphate, acted as an input signal and was specifically recognized by the artificial receptor to form a signal-receptor complex on the membrane surface. The information from the molecular recognition was then transmitted to the enzyme by a copper(II) ion, as a mediator, which increased the enzymatic activity. We found that the efficiency of the molecular information processing in the cerasome was much higher than that in the peptide lipid vesicle. The former advantage comes from an enhanced phase separation of the steroidal receptor in the cerasome than in the peptide lipid membrane, which promotes the formation of a ternary complex of the receptor, signal and mediator species. Energy transfer is another important phenomenon in molecular information processing. Indeed, efficient fluorescence energy transfer between cyanine dyes was achieved with a cerasome formed with lipid (5) (Dai et al., 2009).

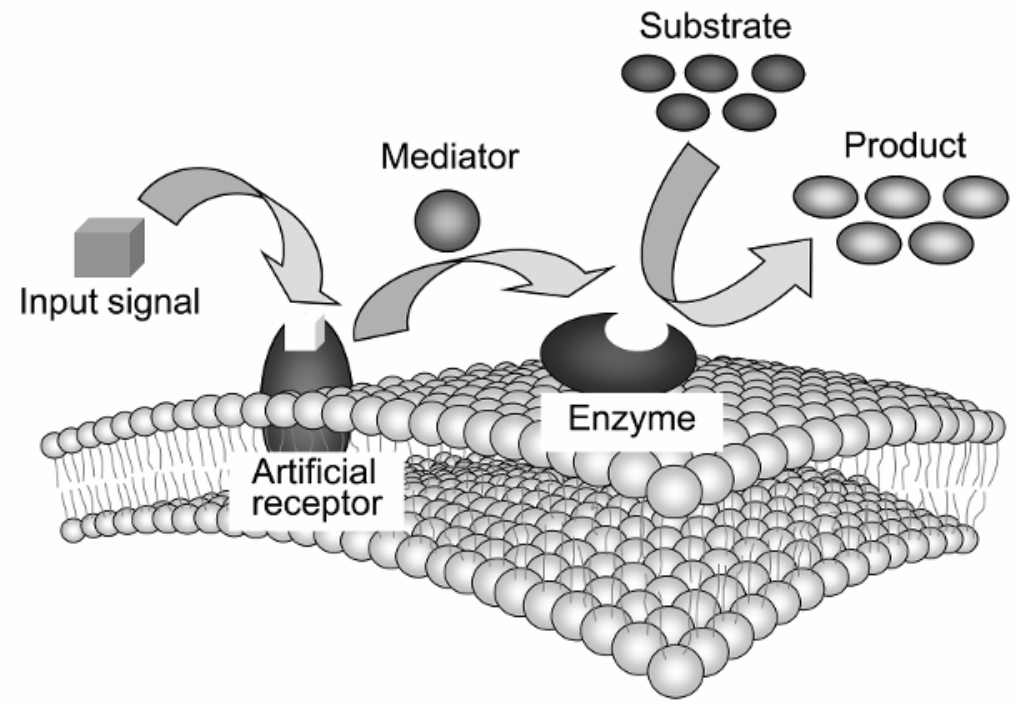

Fig. 11. Schematic representation of molecular information processing on a cerasome. 


\section{Conclusion}

One of the useful guideposts in the creation of intelligent biomimetic materials is the hybridization of the functional building blocks of biological and artificial molecular components (Kikuchi et al., 2004). Cerasomes have been developed as a nanohybrid of membrane-forming lipids and ceramics along this line. Specifically, cerasomes behave as biomembrane models, as well as phospholipid liposomes and synthetic organic lipid vesicles. Owing to the enhanced morphological stability of the cerasome siloxane network on the vesicular surface, the hybrid performs as a superior vesicle in various applications as compared with conventional lipid vesicles. Moreover, cerasomes combine the structural and chemical characteristics of silica particles. Therefore, cerasomes have potential for application in a wide variety of novel functional fields, in which conventional lipid vesicles cannot be employed.

\section{References}

Ariga, K.; Katagiri, K. \& Kikuchi, J. (2000). Preparation condition of a novel organic-inorganic hybrid vesicle "cerasome". Kobunshi Ronbunshu, 57, 4, 251-253, 0386-2186

Behr, J. P. (1993). Synthetic gene-transfer vectors. Acc. Chem. Res., 26, 5, 274-278, 0001-4842

Brockerhoff, H. (1977). Molecular design of membrane lipids, In: Bioorganic Chemistry, Tamelen, E. E., (Ed), Vol. 3, 1-20, Academic Press, 0-12-714303-3, New York

Cölfen, H. \& Mann, S. (2003). Higher-order organization by mesoscale self-assembly and transformation of hybrid nanostructures. Angew. Chem. Int. Ed., 42, 21, 2350-2365, 1443-7851

Dabbs, D. M. \& Aksay, I. A. (2000). Self-assembled ceramics produced by complex-fluid templation. Annu. Rev. Phys. Chem., 51, 601-622, 0066-426X

Dai, Z.-F.; Tian, W.-J.; Yue, X.-L.; Zheng, Z.-Z.; Qi, J.-J.; Tamai, N. \& Kikuchi, J. (2009). Efficient fluorescence resonance energy transfer in highly stable liposomal nanohybrid cerasome. Chem. Commun., 15, 2032-2034, 1359-7345

Felgner, P. L.; Dadek, T. R; Holm, M.; Roman, R.; Chan, H. W.; Wenz, M.; Northrop, J. P.; Ringold, G. M. \& Danielsen, M. (1987). Lipofection: A highly efficient, lipidmediated DNA-transfection procedure. Proc. Nat. Acad. Sci. U.S.A., 84, 21, 74137417, 0027-8424

Feng, P.; Bu, X.; Stucky, G. D. \& Pine, D. J. (2000). Monolithic mesoporous silica templated by microemulsion liquid crystals. el Am. Chem. Soc., 122, 5, 994-995, 0002-7863

Gu, F.; Hashizume, M.; Okada, S.; Sasaki, Y.; Kikuchi, J. \& Imori, T. (2008). Metallosome: An artificial cell membrane with ultrathin metallic surface derived from a cationic cerasome through electroless plating. II Ceram. Soc. efpn., 116, 3, 400-405, $1882-0743$

Hashizume, M.; Kawanami, S.; Iwamoto, S.; Isomoto, T. \& Kikuchi, J. (2003). Stable vesicular nanoparticle "cerasome" as an organic-inorganic hybrid formed with organoalkoxysilane lipids having a hydrogen-bonding unit. Thin Solid Films, 438439, 20-26, 0040-6090

Hashizume, M.; Inoue, H.; Katagiri, K.; Ikeda, A. \& Kikuchi, J. (2004). Cerasome as an organic-inorganic vesicular nanohybrid. Characterization of cerasome-forming 
lipids having a single or a dual trialkoxysilyl head. I Sol-Gel Sci. Technol., 31, 1-3, 99-102, 9028-0707

Hashizume, M.; Saeki, I.; Otsuki, M. \& Kikuchi, J. (2006a). Incorporation of lipid domains in cerasome, a morphologically-stable organic-inorganic vesicular nanohybrid. $\mathscr{C} \mathrm{Sol}$ Gel Sci. Technol., 40, 2-3, 227-232, 0928-0707

Hashizume, M.; Yamada, M.; Katagiri, K.; Tsuji, M. \& Kikuchi, J. (2006b). Facile functionalization of lipid bilayer vesicles by titania: the use of cerasome-forming lipid for surface and core modification. Bioconjugate Chem., 17, 4, 1099-1104, 10431802

Hashizume, M.; Sasaki, Y.; Terashima, T.; Komatsu, T. \& Kikuchi, J. (2008). Creation of organized assembly of cerasomes on DNA templates. Kobunshi Ronbunshu, 65, 6, 421-426, 0386-2186

Hashizume, M.; Horii, H.; Kikuchi, J.; Kamitakahara, M.; Ohtsuki, C. \& Tanihara, M. (2010). Effects of surface carboxylic acid groups of cerasomes, morphologically stable vesicles having a silica surface, on biomimetic deposition of hydroxyapatite in body fluid conditions. el Mater. Sci: Mater. Med., 21, 1, 11-19, 0957-4530

Hubert, D. H. W.; Jung, M.; Frederik, P. M.; Bomans, P. H. H.; Meuldijkm J. \& German, A. L. (2000). Vesicle-directed growth of silica. Adv. Mater., 12, 17, 1286-1290, 0935-9648

Huo, Q.; Margolese, D. I. \& Stucky, G. D. (1996). Surfactant control of phases in the synthesis of mesoporous silica-based materials. Chem. Mater., 8, 5, 1147-1160, 0897-4756

Ikeda, A.; Nagano, M.; Akiyama, M.; Matsumoto, M.; Ito, S.; Mukai, M.; Hashizume, M.; Kikuchi, J.; Katagiri, K.; Ogawa, T. \& Takeya, T. (2009). Photodynamic activity of $\mathrm{C}_{70}$ caged within surface-cross-linked liposome. Chem. Asian J., 4, 1, 199-205, 18614728

Inagaki, S.; Guan, S.; Fukushima, Y.; Ohsuna, T. \& Terasaki, O. (1999). Novel mesoporous materials with a uniform distribution of organic groups and inorganic oxide in their frameworks. \& Am. Chem. Soc., 121, 41, 9611-9614, 0002-7863

Israelachivili, J. N.; Mitchell, D. J. \& Ninham, B. W. (1976). Theory of self-assembly of hydrocarbon amphiphiles into micelles and bilayers. I Chem. Soc. Faraday Trans. 2, 72, 9, 1525-1568, 0300-9238

Kabanov, A. V. \& Kabanov, V. A. (1995). DNA complexes with polycations for the delivery of genetic material into cells. Bioconjugate Chem., 6, 1, 7-20, 1043-1802

Katagiri, K.; Ariga, K. \& Kikuchi, J. (1999). Preparation of organic-inorganic hybrid vesicle "cerasome" derived from artificial lipid with alkoxysilyl head. Chem. Lett., 7, 661662, 0366-7022

Katagiri, K.; Ariga, K. \& Kikuchi, J. (2001). Novel class of organic-inorganic hybrid vesicle "cerasome" derived from various amphiphiles with alkoxysilyl head. Stud. Surface Sci. Catal., 132, 599-602, 0167-2991

Katagiri, K.; Hamasaki, R.; Ariga, K. \& Kikuchi, J. (2002a). Layered paving of vesicular nanoparticles formed with cerasome as a bioinspired organic-inorganic hybrid. $C$ Am. Chem. Soc., 124, 27, 7892-7893, 0002-7863

Katagiri, K.; Hamasaki, R.; Ariga, K. \& Kikuchi, J. (2002b). Layer-by-layer self-assembling of liposomal nanohybrid "cerasome" on substrates. Langmuir, 18, 17, 6709-6711, 07437463 
Katagiri, K.; Hamasaki, R.; Ariga, K. \& Kikuchi, J. (2003). Preparation and surface modification of novel vesicular nano-particle "cerasome" with liposomal bilayer and silicate surface. I Sol-Gel Sci. Technol., 26, 1-3, 393-396, 0928-0707

Katagiri, K.; Hashizume, M.; Kikuchi, J.; Taketani, Y. \& Murakami, M. (2004a). Creation of asymmetric bilayer membrane on monodispersed colloidal silica particles. Colloids Surf. B, 38, 1-3, 149-153, 0927-7765

Katagiri, K.; Hamasaki, R.; Hashizume, M.; Ariga, K. \& Kikuchi, J. (2004b). Size-selective organization of silica and silica-like particles on solid interfaces through layer-bylayer assembly. I Sol-Gel Sci. Technol., 31, 1-3, 59-62, 0928-0707

Katagiri, K.; Hashizume, M.; Ariga, K.; Terashima, T. \& Kikuchi, J. (2007). Preparation and characterization of a novel organic-inorganic nanohybrid "cerasome" formed with a liposomal membrane and silicate surface. Chem. Eur. J., 13, 18, 5272-5281, 0947-6539

Kikuchi, J.; Ariga, K. \& Ikeda, K. (1999). Signal transduction mediated by artificial cellsurface receptors. Activation of lactate dehydrogenase triggered by molecular recognition and phase separation of bile acid derivatives embedded in a synthetic bilayer membrane. Chem. Commun., 6, 547-548, 1359-7354

Kikuchi, J.; Ikeda, A. \& Hashizume, M. (2004). Biomimetic materials, In: Encyclopedia of Biomaterials and Biomedical Engineering, Vol. 1, Wnek, G. E. \& Bowlin, G. L., (Eds.), 96-102, Marcel Dekker, 0-8247-5498-0, New York

Kikuchi, J. \& Yasuhara, K. (in press) Microscopy \& micro/nano imaging techniques: TEM, In: Supramolecular Chemistry: From Molecules to Nanomaterials, Vol. 1, Steed, J. W. \& Gale, P. A., (Eds.), John Wiley \& Sons, in press, Chichester

Krämer, E.; Förster, S.; Göltner, C. \& Antonietti, M. (1998). Synthesis of nanoporous silica with new pore morphologies by templating the assemblies of ionic block copolymers. Langmuir, 14, 8, 2027-2031, 0743-7463

Kresge, C. T.; Leonowicz, M. E.; Roth, W. J.; Vartuli, J. C. \& Beck, J. S. (1992). Ordered mesoporous molecular sieves synthesized by a liquid-crystal template mechanism. Nature, 359, 6397, 710-712, 0028-0836

Kunitake, T. (1992). Synthetic bilayer membranes: molecular design, self-organization, and application. Angew. Chem. Int. Ed. Engl., 31, 6, 709-726, 0570-0833

Luisi, P. L. \& Walde P. (1999). Giant Vesicles, John Wiley \& Sons, 0471-97986-4, Chichester

Mackenzie, J. D. (1994). Structure and properties of ormosils. el Sol-Gel Sci. Technol., 2, 1-3, 81-86, 9028-0707

Matsui, K.; Sando, S.; Sera, T.; Aoyama, Y.; Sasaki, Y.; Komatsu, T.; Terashima, T. \& Kikuchi, J. (2006). Cerasome as an infusible, cell-friendly, and serum-compatible transfection agent in a viral size. $J$ Am. Chem. Soc., 128, 10, 3114-3115, 0002-7863

Matsui, K.; Sasaki, Y.; Komatsu, T.; Mukai, M.; Kikuchi, J. \& Aoyama, Y. (2007). RNAi gene silencing using cerasome as a vial-size siRNA-carrier free from fusion and crosslinking. Bioorg. Med. Chem. Lett., 17, 14, 3935-3938, 0960-894X

Melosh, N. A.; Lipic, P.; Bates, F. S.; Wudl, F.; Stucky, G. D.; Fredrickson, G. H. \& Chmelka, B. F. (1999). Molecular and mesoscopic structures of transparent block copolymersilica monoliths. Macromolecules, 32, 13, 4332-4342, 0024-9297 
Minamida, D.; Okada, S.; Hashizume, M.; Sasaki, Y.; Kikuchi, J.; Hosoito, N. \& Imori, T. (2008). Creation of magnetic cerasomes through electroless plating and their manipulation using external magnetic fields. I Sol-Gel Sci. Technol., 48, 1-2, 95-101, 0928-0707

Mintzer, M. A. \& Simanek, E. E. (2009). Nonviral vectors for gene delivery. Chem. Rev., 109, 2, 259-302, 0009-2665

Moreau, J. J. E.; Vellutini, L.; Man, M. W. C. ; Bied, C. ; Bantignies, J. L. ; Dieudonné, P. \& Sauvajol, J.-L. (2001). Self-organized hybrid silica with long-range ordered lamellar structure. I Am. Chem. Soc., 123, 32, 7957-7958, 0002-7863

Mueller, A. \& O'Brien, D. F. (2002). Supramolecular materials via polymerization of mesophases of hydrated amphiphiles. Chem. Rev., 102, 3, 727-757, 0009-2665

Murakami, Y. \& Kikuchi, J. (1991). Supramolecular assemblies formed with synthetic peptide lipids. Functional models of biomembranes and enzymes, In: Bioorganic Chemistry Frontiers, Vol. 2, Dugas, H. (Ed.), 73-113, Springer, 3-540-53365-6, Berlin

Nishimori, H.; Tatsumisago, M. \& Minami, T. (1996). Influence of size of dispersed silica particles on preparation of thick silica films by using electrophoretic sol-gel deposition, Bull. Chem. Soc. cpn., 69, 3, 815- 818, 0009-2673

Ono, Y.; Nakashima, K.; Sano, M.; Kanekiyo, Y.; Inoue, K.; Hojo, J. \& Shinkai, S. (1998). Organic gels are useful as a template for the preparation of hollow fiber silica. Chem. Commun., 14, 1477-1478, 1359-7345

Ozin, G. A. (2000). Panoscopic materials: synthesis over 'all' length scales. Chem. Commun., 6, 419-432, 1359-7345

Ruiz-Hitzky, E.; Letaïef, S. \& Prévot, V. (2002). Novel organic-inorganic mesophases: Selftemplating synthesis and intratubular swelling. Adv. Mater., 14, 6, 439-443, 09359648

Ryoo, R.; Ko, C. H.; Kruk, M.; Antochshuk, V. \& Jaroniec, M. (2000). , Block-copolymertemplated ordered mesoporous silica: Array of uniform mesopores or mesoporemicropore network? \&l Phys. Chem. B, 104, 48, 11465-11471, 1520-6106

Sakata, K. \& Kunitake, T. (1990). A multilayered film of an ultrathin siloxane network. $d$ Chem. Soc. Chem. Commun. 1990, 6, 504-505, 0022-4936

Sakka, S. (Ed.) (2005). Handbook of Sol-Gel Science and Technology, Vol. 1, Kluwer Academic, 14020-7966-4, Boston

Sanchez, C.; Soler-Illia, G. J. de A. A.; Ribot, F.; Lalot, T.; Mayer, C. R. \& Cabuil, V. (2001). Designed hybrid organic-inorganic nanocomposites from functional nanobuilding blocks. Chem. Mater., 13, 10, 3061-3083, 1897-4756

Sasaki, Y.; Yamada, M.; Terashima, T.; Wang, J.-F.; Hashizume, M.; Fan, S.-D. \& Kikuchi, J. (2004). Construction of intermolecular communication system on "cerasome" as an organic-inorganic nanohybrid. Kobunshi Ronbunshu, 61, 10, 541-546, 0386-2186

Sasaki, Y.; Matsui, K.; Aoyama, Y. \& Kikuchi, J. (2006). Cerasome as an infusible and cellfriendly gene carrier: Synthesis of cerasome-forming lipids and transfection using cerasome. Nat. Protocols, 1, 3, 1227-1234, 1754-2189

Schmidt, H. (1994). Inorganic-organic composites by sol-gel techniques. \& Sol-Gel Sci. Technol., 1, 3, 217-231, 9028-0707 
Schottner, G. (2001). Hybrid sol-gel-derived polymers: applications of multifunctional materials. Chem. Mater., 13, 10, 3422-3435, 1897-4756

Scott, B. J.; Wirnsberger, G. \& Stucky, G. D. (2001). Mesoporous and mesostructured materials for optical applications. Chem. Mater., 13, 10, 3140-3150, 1897-4756

Shimojima, A.; Sugahara, Y. \& Kuroda, K. (1997). Inorganic-organic layered materials derived via the hydrolysis and polycondensation of trialkoxy(alkyl)silanes. Bull. Chem. Soc. epn., 70, 11, 2847-2853, 0009-2673

Sims, S. D.; Walsh, D. \& Mann, S. (1998). Morphosynthesis of macroporous silica frameworks in bicontinuous microemulsions. Adv. Mater., 10, 2, 151-154, $0935-$ 9648

Tian, W.-J.; Sasaki, Y.; Fan, S.-D. \& Kikuchi, J. (2005). Switching of enzymatic activity through functional connection of molecular recognition on lipid bilayer membranes. Supramol. Chem., 17, 1-2, 113-119, 1061-0278

Torchilin, V. P. \& Weissig, V. (2003). Liposomes, 2nd ed., Oxford Univ. Press, 0-19-963654-0, Oxford

Ulman, A. (1996). Formation and structure of self-assembled monolayers. Chem. Rev., 96, 4, 1533-1554, 0009-2665

van Bommel, K. J. C.; Friggeri, A. \& Shinkai, S. (2003). Organic templates for the generation of inorganic materials. Angew. Chem. Int. Ed., 42, 9, 980-999, 1443-7851

Yanagisawa, T.; Shimizu, T.; Kuroda, K. \& Kato, C. (1990). The preparation of alkyltrimethylammonium-kanemite complexes and their conversion to microporous materials. Bull. Chem. Soc. .pn., 63, 4, 988-992, 0009-2673

Zhang, Q.; Ariga, K.; Okabe, A. \& Aida, T. (2004). A condensable amphiphile with a cleavable tail as a "lizard" template for the sol-gel synthesis of functionalized mesoporous silica. I Am. Chem. Soc., 126, 4, 988-989, 0002-7863 


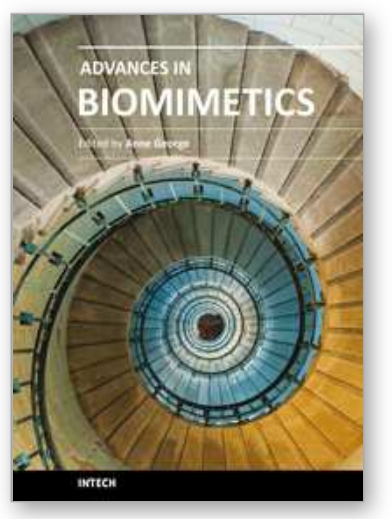

\author{
Advances in Biomimetics \\ Edited by Prof. Marko Cavrak
}

ISBN 978-953-307-191-6

Hard cover, 522 pages

Publisher InTech

Published online 26, April, 2011

Published in print edition April, 2011

The interaction between cells, tissues and biomaterial surfaces are the highlights of the book "Advances in Biomimetics". In this regard the effect of nanostructures and nanotopographies and their effect on the development of a new generation of biomaterials including advanced multifunctional scaffolds for tissue engineering are discussed. The 2 volumes contain articles that cover a wide spectrum of subject matter such as different aspects of the development of scaffolds and coatings with enhanced performance and bioactivity, including investigations of material surface-cell interactions.

\title{
How to reference
}

In order to correctly reference this scholarly work, feel free to copy and paste the following:

Jun-ichi Kikuchi and Kazuma Yasuhara (2011). Cerasomes: A New Family of Artificial Cell Membranes with Ceramic Surface, Advances in Biomimetics, Prof. Marko Cavrak (Ed.), ISBN: 978-953-307-191-6, InTech, Available from: http://www.intechopen.com/books/advances-in-biomimetics/cerasomes-a-new-family-ofartificial-cell-membranes-with-ceramic-surface

\section{INTECH}

open science | open minds

\section{InTech Europe}

University Campus STeP Ri

Slavka Krautzeka 83/A

51000 Rijeka, Croatia

Phone: +385 (51) 770447

Fax: +385 (51) 686166

www.intechopen.com

\section{InTech China}

Unit 405, Office Block, Hotel Equatorial Shanghai

No.65, Yan An Road (West), Shanghai, 200040, China 中国上海市延安西路65号上海国际贵都大饭店办公楼 405 单元

Phone: +86-21-62489820

Fax: +86-21-62489821 
(C) 2011 The Author(s). Licensee IntechOpen. This chapter is distributed under the terms of the Creative Commons Attribution-NonCommercialShareAlike-3.0 License, which permits use, distribution and reproduction for non-commercial purposes, provided the original is properly cited and derivative works building on this content are distributed under the same license. 